larger suture knot might be more likely to cause abrasion and irritation of the nasal mucosa. Thus far this has not been a problem. Because of the almost nonexistent biodegradability of polypropylene, the 6-0 suture has retained sufficient strength to resist prolapse of the stents.

The idea of securing the two loops of the stent together at the time of dacryocystorhinostomy to prevent prolapse remains an excellent one. We would suggest that other surgeons may wish to substitute 6-0 polypropylene suture for the 4-0 silk suture should their patients also develop complaints of a foul odor postoperatively.

ROBERT C. KERSTEN, MD

Dwight R. Kulwin, MD Cincinnati

1. Jordan DR, Anderson RL: Prevention of prolapsed silicone stents in dacrocystorhinostomy surgery. Arch Ophthalmol 1987;105:455.

2. Stillman RM, Bella FJ, Seligman JJ: The effect of various wound closure methods on susceptibility to infection. Arch Sury 1980;115:674-675. 3. Mouzas GL, Yeadon A: Does the choice of suture material affect the incidence of wound infection? Br J Sury 1975;62:952-955.

In Reply.-We would like to thank Drs Kersten and Kulwin for their suggestions. We agree with their assertion that a silk suture represents more of nidus for infection than does a polypropylene suture. Therefore, we have also switched to monofilament suture to secure the two arms of the silicone stent. However, one of our patients had an extrusion after we switched to a monofilament suture and we believe that the suture must be tied tightly and is probably less secure than the silk suture. In addition, the monofilament suture may "cheesewire" through the stent if it is tied too tightly in these cases.

We have had some patients with or without silk sutures complain of a malodorous discharge from the nose with a silicone stent in place. In many cases we believe that this is the result of an allergy to the silicone and it is usually relieved by removal of the stent.

In summary, we agree with Drs Kersten and Kulwin that it is preferable to use a polypropylene or other monofilament suture to secure silicone stents in the nose.

RICHARD L. ANDERSON, MD

DAVID R. JORDAN, MD

Salt Lake City

\section{The Variprism: A Large-Range Variable Prism for Measurement of the Angle of Squint}

To the Editor.-Prism bars and variable Herschel prisms are most commonly used today to measure the angle of squint. Both have drawbacks, however. Prism bars are too large to carry around all day and are usually limited to 40 prism diopters (PD), while variable Herschel prisms have even smaller ranges. Hans Meester and I have therefore developed, at the Netherlands Ophthalmic Research Institute, Amsterdam, a hand-held prism that is continuously variable over a large range, horizontally as well as vertically. We propose to call it the "Variprism." It consists of a small housing containing two glass elements, ie, planoconvex and planoconcave, with equal radii of the convex and concave surfaces (Fig 1). The planoconvex front element is a half globe, freely rotatable in gimbals. The planoconcave lens is situated immediately behind it. The two optical elements function as a single prism, the front surface of which can be tilted in all directions. The distance between the convex surface of the half globe and the concave surface of the planoconcave lens is approximately $0.1 \mathrm{~mm}$. The disturbances resulting from this air gap, ie, decreased

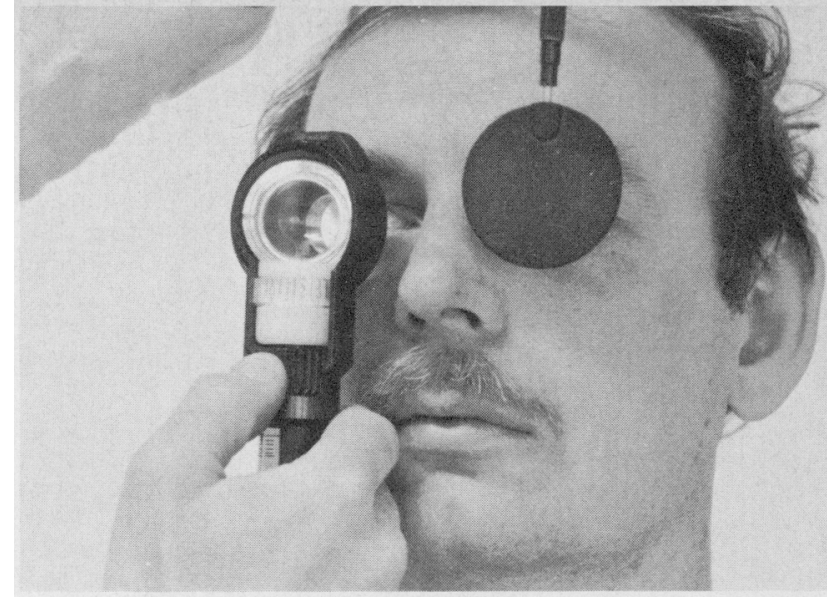

Fig 1.-Prototype of Variprism. Note glass half globe suspended in gimbals. Horizontal setting can be changed by rotating black wheel and vertical setting can be changed by rotating white wheel.

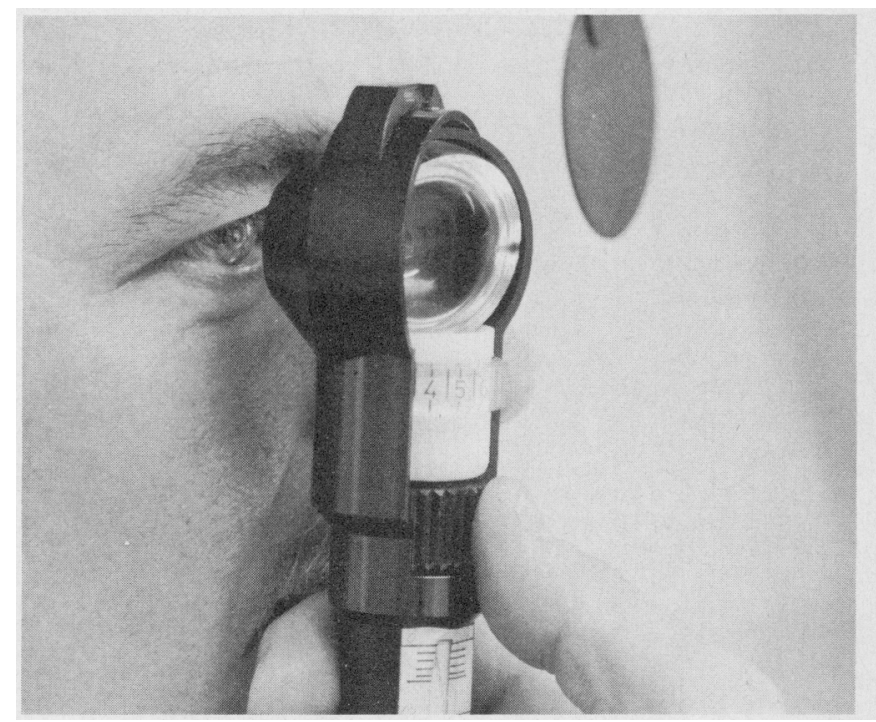

Fig 2.-Eye movements can be observed from side while performing alternate cover test.

transmission of light and distortion when out-of-roundness is present, are minor.

The setting of the prism can be varied continuously between $-45^{\circ}$ and $+45^{\circ}(-90$ to $+90 \mathrm{PD})$ horizontally and between $-8^{\circ}$ and $+8^{\circ}(-15$ and $+15 \mathrm{PD})$ vertically, with two wheels operated by the thumb of the hand holding the Variprism. The horizontal setting is shown in a slit in the grip of the device (Fig 2), while the vertical setting is indicated on the wheel, both in degrees and in prism diopters. A spirit is added for accurate measurements of large angles.

H. J. Simonsz, MD Amsterdam

The author has no commercial, proprietary, or financial interest in the Variprism. The manufacture of the prototype of the Variprism was made possibile by the Vision Research Foundation, Amsterdam, a nonprofit organization that gives financial support to scientific institutions for the development of new devices in ophthalmology. A limited series will be made on a nonprofit basis for those interested.

Requests to Netherlands Ophthalmic Research Institute, PO Box 12141, NL1100 AC Amsterdam, Holland. 